\title{
Phenological basis of determining tourism seasons for ornamental plants in central and eastern China
}

\author{
TAO Zexing ${ }^{1,2}$, GE Quansheng ${ }^{1}$, WANG Huanjiong ${ }^{1,2}$, "DAI Junhu ${ }^{1}$ \\ 1. Key Laboratory of Land Surface Pattern and Simulation, Institute of Geographic Sciences and Natural Re- \\ sources Research, CAS, Beijing 100101, China; \\ 2. University of Chinese Academy of Sciences, Beijing 100049, China
}

\begin{abstract}
Many plants have high ornamental value during specific phenophases, and plant phenology correlates highly with seasonal vegetation landscape. Determination of the span and spatiotemporal patterns of the tourism season for ornamental plants could provide tourism administrators and the tourists themselves with a theoretical basis for making travel arrangements. Based on data derived from on-the-ground observations of three phenophases, specifically first leafing date, full flowering date, and end of leaf coloring date, and corresponding meteorological data at 12 sites in China, we divided the tourism season into its starting date, peak (best date) and end date for ornamental plants by computing frequency distributions of these phenophases. We also determined how the peak of this tourism season changed during the course of the past 50 years. We found that: (1) The peak of the tourism season ranged from March 16 (in Guilin) to May 5 (in Harbin) for first leafing, from April 3 (in Kunming) to May 24 (in Mudanjiang) for full flowering, and from October 1 (in Mudanjiang) to November 30 (in Shanghai) for leaf coloring. As might be expected, the peaks of both the first leafing and full flowering tourism seasons were positively associated with latitude, while for leaf coloring it was negatively correlated with latitude. (2) The ideal tourism season for first leafing and full flowering advanced by more than 0.16 days/year over the past 50 years in Beijing and Xi'an, while the peak of the tourism season for leaf coloring became significantly delayed (by 0.16 days/year in Beijing and 0.21 days/year in Xi'an). (3) The tourism season was significantly associated with temperature across related phenological observation sites. The ideal time for first leafing and full flowering was determined to have advanced, respectively, by 4.02 days and 4.04 days per $1^{\circ} \mathrm{C}$ increase in the spring (March-May) temperature. From September to November, the best time for leaf coloring correlated significantly and positively with average temperature, and the spatial sensitivity was 2.98 days $/{ }^{\circ} \mathrm{C}$.
\end{abstract}

Keywords: phenology; vegetation landscape; tourism season; temperature change

\section{Introduction}

Phenophases such as first leafing, flowering and leaf coloring represent the different phases

Received: 2015-03-21 Accepted: 2015-05-08

Foundation: National Natural Science Foundation of China, No.41171043; National Basic Research Program of China, No.2012CB955304; Major National Research Program of Scientific Instruments, No.41427805; National Natural Science Foundation of China, No.41030101

Author: Tao Zexing, PhD Candidate, specialized in phenology, plant and climate change. E-mail: colwhoo@163.com

*Corresponding author: Dai Junhu, PhD and Professor, E-mail: daijh@igsnrr.ac.cn 
of the growth of plants. During the growing seasons, the organs of plants (e.g., their flowers and leaves) show distinctive morphological and physiological characteristics (Yang and Zhu, 2011), which produce a variety of landscapes with high ornamental values throughout the year. Therefore, plant phenology has a close relationship with how seasonal vegetation affects the landscape. In recent decades, tourism activities based on viewing plants have become popular around the world. For instance, the cherry blossom festivals in Tokyo and Kyoto, Japan and the red autumnal leaves and peach blossom in China have attracted many tourists (Chen, 2007; Ma and Fang, 2006). Such events appear to strongly stimulate the tourism market. It should thus be very beneficial to schedule tourism activities based on applications of phenological theories.

Previous phenological studies proved that the interannual variations of plant phenophases in temperate humid and semi-humid regions of the Northern Hemisphere have mainly been controlled by temperature (Menzel et al., 2006; Cleland et al., 2007). Climate change over the past several decades has led to a shift in both when plant phenophases begin and for how long they last (Ge et al., 2014; Dai et al., 2013). Vegetation landscapes such as first leafing, full flowering and leaf coloring only last for a limited period of time (Zhang and Yang, 2006), so changes in plant phenophases affect the best time periods of the year to view ornamental plants. For example, Ge et al. (2013) studied the influence of change in temperature between 1963 and 2010 on leaf coloring of Acer mono in Beijing and Xi'an. They found a significant delay in fall foliage vacations to view leaf coloring. Ma and Fang (2006) analyzed the influence of climate warming on spring phenology in Beijing, and demonstrated that the duration of Prunus davidiana flowering in the Beijing Botanical Garden was prolonged significantly between 1989 and 2005. Therefore, plant phenology is of great value to provide a theoretical basis for evaluating the effects of climate change on tourism activities (Ge et al., 2013; Bell et al., 2007).

Vegetation landscape properties that are based on plant phenophases such as first leafing, full flowering and leaf coloring could influence the behavior of tourists as well as regional tourism demands (Bao and $\mathrm{Chu}, 2012$ ). Phenology thus provides good guidance for activities of tourists interested in ornamental plants. Previous studies have applied phenological models to predict plant flowering. For example, Zhang et al. (2014) compared the applicability of several phenological models in predicting plant flowering time in Beijing and predict the flowering time of three ornamental plants successfully. Some studies have found their way into Japanese television and its daily broadcasts of the cherry blossom forecast. These studies, however, rarely consider phenology and tourism geography together. It is worth studying the relationship between phenology and tourism, because it can help explain the behavior of tourists and guide tourism activities.

Based on long-term phenological observations at 12 sites of the China Phenological Observation Network (CPON), we determined the span of the ornamental plant tourism season-including its onset, peak (i.e., best date), and end date - for most of the past 50 years, and analyzed this information to uncover any changes during the course of this time period. We also studied the spatial difference and the temperature sensitivity of the peak of the tourism season. Our goal is to help tourism administrative departments arrange viewing activities of ornamental plants and develop tourism strategies by having them take climate change into account. 


\section{Data and methods}

\subsection{Phenological and meteorological data}

Phenological data (1963-2009) in this study were derived from the Chinese Phenological Observation Network (CPON). To analyze the differences of the tourism seasons among disparate regions of China, we selected 12 sites across much of the central and eastern parts of the country (Table 1). According to the map of Chinese Vegetation Regionalization (Hou, 2001) shown in Figure 1, Beijing, Xi'an and Luoyang are located in warm temperate deciduous broadleaf forest regions; Harbin is located in a temperate grassland region; Mudanjiang is located in a temperate coniferous and broadleaf mixed forest region; and Chongqing,

Table 1 Observation sites, duration and number of species for phenological data in this study

\begin{tabular}{lccccc}
\hline \multicolumn{1}{c}{ Sites } & \multicolumn{1}{c}{ Location } & $\begin{array}{c}\text { Observation } \\
\text { start year }\end{array}$ & $\begin{array}{c}\text { Observation } \\
\text { end year }\end{array}$ & $\begin{array}{c}\text { Observed } \\
\text { years }\end{array}$ & $\begin{array}{c}\text { Number of } \\
\text { plants }\end{array}$ \\
\hline Harbin & $45.75^{\circ} \mathrm{N}, 126.63^{\circ} \mathrm{E}$ & 1963 & 2009 & 25 & 241 \\
Mudanjiang & $43.50^{\circ} \mathrm{N}, 129.80^{\circ} \mathrm{E}$ & 1965 & 1996 & 22 & 125 \\
Beijing & $40.02^{\circ} \mathrm{N}, 116.33^{\circ} \mathrm{E}$ & 1963 & 2009 & 40 & 84 \\
Luoyang & $34.53^{\circ} \mathrm{N}, 112.30^{\circ} \mathrm{E}$ & 1964 & 1997 & 30 & 96 \\
Xi'an & $34.22^{\circ} \mathrm{N}, 108.97^{\circ} \mathrm{E}$ & 1963 & 2009 & 35 & 240 \\
Shanghai & $31.20^{\circ} \mathrm{N}, 121.00^{\circ} \mathrm{E}$ & 1963 & 2009 & 25 & 108 \\
Wuhan & $30.52^{\circ} \mathrm{N}, 114.31^{\circ} \mathrm{E}$ & 1963 & 2009 & 21 & 59 \\
Hangzhou & $30.27^{\circ} \mathrm{N}, 120.16^{\circ} \mathrm{E}$ & 1963 & 1984 & 14 & 229 \\
Chongqing & $29.82^{\circ} \mathrm{N}, 106.33^{\circ} \mathrm{E}$ & 1963 & 2009 & 29 & 83 \\
Guiyang & $26.42^{\circ} \mathrm{N}, 106.67^{\circ} \mathrm{E}$ & 1963 & 2009 & 31 & 139 \\
Guilin & $25.18^{\circ} \mathrm{N}, 110.20^{\circ} \mathrm{E}$ & 1964 & 2009 & 33 \\
Kunming & $25.04^{\circ} \mathrm{N}, 102.73^{\circ} \mathrm{E}$ & 1963 & 2009 & 17 & 136 \\
\hline
\end{tabular}

\section{Vegetation Region}

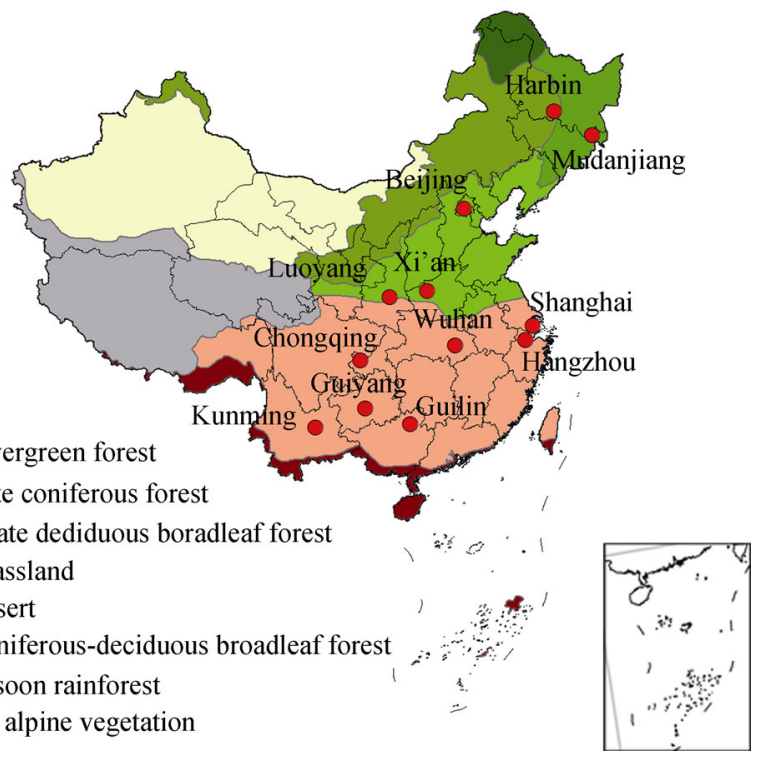

Figure 1 The 12 sites of this study on a vegetation map of China 
Wuhan, Hangzhou, Kunming, Guiyang, Guilin and Shanghai are located in subtropical evergreen broadleaf forest regions.

Considering that tourists enjoy the sights of leaf unfolding and flower blossoming in the spring and leaf coloring in the autumn, we chose the first leafing date, full flowering date and leaf coloring date as the three phenophases for studying the characteristics of tourism season. At each site, different numbers of widespread species with obvious landscapes of leaf unfolding, blossoming and leaf coloring were investigated (Table 1). Since evergreen plants do not display an apparent leaf coloring process in the autumn, all of the species selected in this study were deciduous plants.

Meteorological data at each site, including monthly average temperatures between 1963 and 2009, were obtained from the China Meteorological Data Sharing Service System (http://cdc.cma.gov.cn) (Bai et al., 2010).

\subsection{Methods}

The tourism seasons for this study can be defined as the periods during which leaf unfolding, blossoming and leaf coloring occur for most ornamental plants, which is when these phenophases occur most frequently. Therefore, frequency distribution analysis can be used in determining the tourism season. First, we calculated the average first leafing, full flowering and leaf coloring dates of each species between 1963 and 2009 at each of the 12 sites. Then we set 10 days as the interval (throughout the year) for determining the frequency of each phenophase at each site (Chen and Cao, 1999). Lastly, a normal distribution function was applied to fit the frequency distribution. The formula is as follows:

$$
y=y_{0}+A e^{-\frac{\left(x-x_{c}\right)^{2}}{2 w^{2}}}
$$

where $y$ is the probability density, $x$ is the day of the year (DOY, the number of days from January 1), $x_{c}$ is expectation, $w$ is the standard deviation, and $y_{0}$ and $A$ are parameters.

In such a normal distribution function, the probability of a value ranging from $x_{c}-w$ to $x_{c}+w$ is $68.27 \%$. In other words, phenophases of more than $2 / 3$ of plant species occur during the period $\left[x_{c}-w, x_{c}+w\right]$, and this period was defined as the tourism season. Furthermore, $x_{c}$ was defined as the peak of the tourism season, and $x_{c}-w$ and $x_{c}+w$ the start and end of the tourism season, respectively.

To determine how the peak of the tourism season changes from year to year, we also computed the peak for each of the three phenophases at each site for each (available) year from 1963 to 2009 and then applied linear regression to analyze the trends of these dates.

Since plant phenophases are significantly impacted by temperature (Bai et al., 2010), we analyzed the relationship between the peak of first leafing as well as of flowering and spring (March-May) temperature, and the relationship between the peak of leaf coloring and autumn (September-November) temperature across sites, by applying the linear regression method.

\section{Results}

\subsection{Frequency distribution of plant phenophases}

Most of the measured frequency distributions for each phenophase/site followed a normal 
distribution (Figure 2). Table 2 shows the adjusted $\mathrm{R}^{2}$ values between the measured and normal distributions. For most of the phenophases/sites $(77.8 \%)$, this $\mathrm{R}^{2}$ was greater than 0.8 $(P<0.05$, Table 2). However, the frequency distribution of the full flowering date in Shanghai and first leafing date in Chongqing showed double peaks and the frequency distributions of the full flowering date in Chongqing, Guilin and Guiyang were dispersed. These phenophases/sites cannot been fitted well using equation (1), so they were not considered in our subsequent analysis.
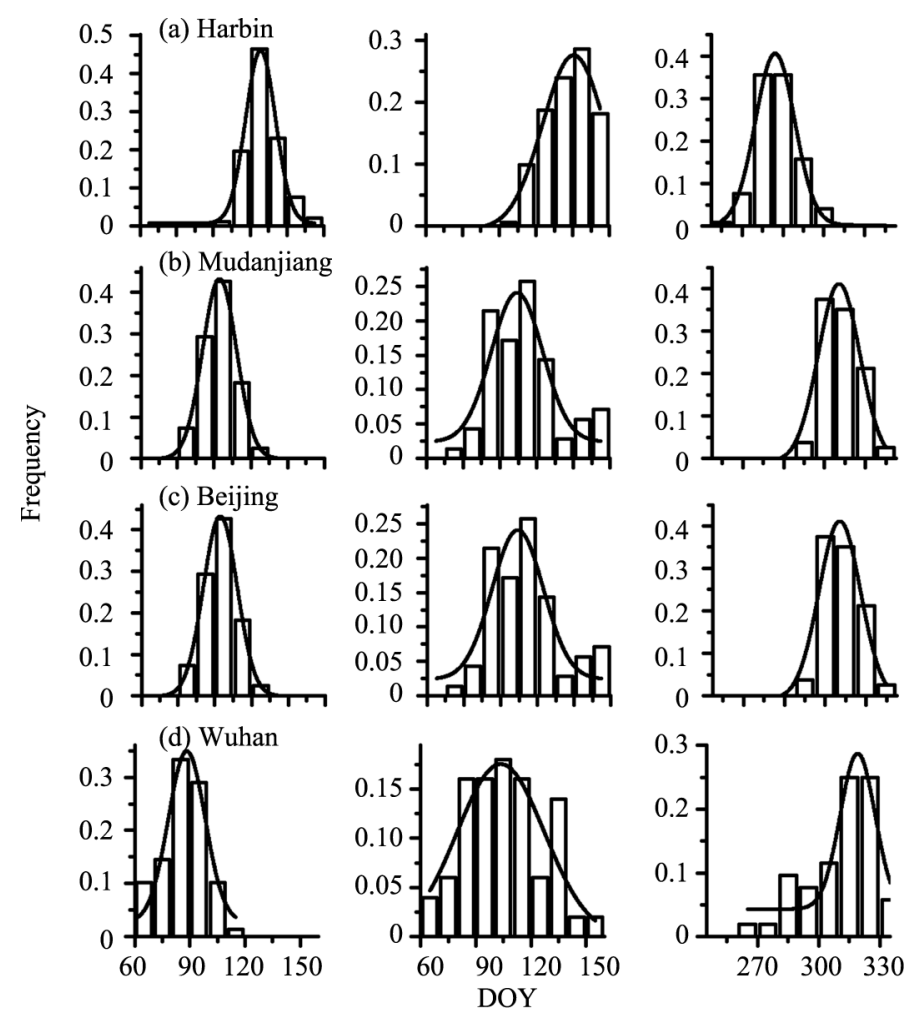

Figure 2 The frequency distributions (bar graphs) and fitted normal distributions (curves) for the measured plant phenophases at representative sites; left: first leafing date; middle: full flowering date; right: full coloring date

\subsection{Determination of the tourism season}

The tourism season for each phenophase of ornamental plants at each of the 12 sites is shown in Table 3. The average best date for viewing the first leafing was April 4; the earliest was in Guilin (March 16); and the latest was in Harbin (May 5). The average duration for viewing the first leafing from all the sites was 20 days. The average best date for viewing the first flowering was April 23; the earliest was in Kunming (April 3); the latest was in Mudanjiang (May 24). The average duration for viewing first flowering was 29 days. The average best date for viewing leaf coloring was November 2, while the earliest and the latest dates were in Mudanjiang (October 1) and Shanghai (November 30), respectively. The average duration for viewing leaf coloring was 22 days. In addition, the tourism season of first leafing overlapped with the tourism season of full flowering at most sites. 
Table 2 The model parameters for simulating the frequency distribution of three phenophases at each site

\begin{tabular}{|c|c|c|c|c|c|c|c|c|c|}
\hline Sites & $\begin{array}{l}\text { Pheno- } \\
\text { phases }\end{array}$ & $\mathrm{X}_{\mathrm{c}}$ & $\mathrm{w}$ & Adjusted $\mathrm{R}^{2}$ & Sites & $\begin{array}{l}\text { Pheno- } \\
\text { phases }\end{array}$ & $\mathrm{X}_{\mathrm{c}}$ & w & $\begin{array}{c}\text { Adjusted } \\
R^{2}\end{array}$ \\
\hline \multirow{3}{*}{ Harbin } & FLD & 126 & 8 & $0.98^{* *}$ & \multirow{3}{*}{$\begin{array}{l}\text { Mudanji- } \\
\text { ang }\end{array}$} & FLD & 125 & 7 & $0.99^{*}$ \\
\hline & FFD & 141 & 17 & $0.98^{* *}$ & & FFD & 145 & 5 & $0.97^{* *}$ \\
\hline & LCD & 276 & 10 & $0.98^{* *}$ & & LCD & 275 & 4 & $0.99^{* *}$ \\
\hline \multirow{3}{*}{ Beijing } & FLD & 103 & 9 & $0.99^{* *}$ & \multirow{3}{*}{ Luoyang } & FLD & 95 & 6 & $0.99^{*}$ \\
\hline & FFD & 109 & 14 & $0.70^{* *}$ & & FFD & 118 & 6 & $0.99^{* *}$ \\
\hline & LCD & 307 & 10 & $0.92^{* *}$ & & LCD & 311 & 4 & $0.99^{* *}$ \\
\hline \multirow{3}{*}{ Xi'an } & FLD & 92 & 12 & $0.99^{* *}$ & \multirow{3}{*}{ Shanghai } & FLD & 90 & 17 & $0.81^{* *}$ \\
\hline & FFD & 103 & 23 & $0.84^{* *}$ & & FFD & - & - & - \\
\hline & LCD & 309 & 15 & $0.99^{* *}$ & & LCD & 335 & 9 & $0.95^{* *}$ \\
\hline \multirow{3}{*}{ Wuhan } & FLD & 88 & 10 & $0.92^{* *}$ & \multirow{3}{*}{ Hangzhou } & FLD & 99 & 10 & $0.96^{* *}$ \\
\hline & FFD & 104 & 24 & $0.62^{* *}$ & & FFD & 105 & 5 & $0.75^{* *}$ \\
\hline & LCD & 319 & 9 & $0.84^{* *}$ & & LCD & 307 & 11 & $0.96^{* *}$ \\
\hline \multirow{3}{*}{ Chongqing } & FLD & - & - & - & \multirow{3}{*}{ Guiyang } & FLD & 77 & 11 & $0.91^{* *}$ \\
\hline & FFD & - & - & - & & FFD & - & - & - \\
\hline & LCD & 325 & 8 & $0.87^{* *}$ & & LCD & 319 & 15 & $0.91^{* *}$ \\
\hline \multirow{3}{*}{ Guilin } & FLD & 76 & 10 & $0.89^{* *}$ & \multirow{3}{*}{ Kunming } & FLD & 76 & 7 & $0.67^{* *}$ \\
\hline & FFD & - & - & - & & FFD & 94 & 24 & $0.73^{* *}$ \\
\hline & LCD & 306 & 15 & 0.4 & & LCD & 300 & 23 & $0.84^{* *}$ \\
\hline
\end{tabular}

Note: FLD: first leafing date; FFD: full flowering date; LCD: leaf coloring date. ${ }^{* *} P<0.01 * P<0.05$; adjusted $\mathrm{R}^{2}$ represents the goodness of fit; - indicates the fit is bad or cannot fit; each integer under $X c$ represents the DOY of the peak, and each one under $w$ represents the length in days of one standard deviation, of the indicated phenophase at the indicated site.

Table 3 Ornamental tourism seasons of three phenophases at each site

\begin{tabular}{|c|c|c|c|c|c|c|c|c|c|}
\hline Sites & $\begin{array}{l}\text { Pheno- } \\
\text { phases }\end{array}$ & Peak & Start & End & Sites & $\begin{array}{l}\text { Pheno- } \\
\text { phases }\end{array}$ & Peak & Start & End \\
\hline \multirow{3}{*}{ Harbin } & FLD & $5-5$ & $4-27$ & $5-13$ & \multirow{3}{*}{$\begin{array}{l}\text { Mudan- } \\
\text { jiang }\end{array}$} & FLD & $5-4$ & $4-27$ & $5-11$ \\
\hline & FFD & $5-20$ & $5-3$ & $6-6$ & & FFD & $5-24$ & $5-19$ & $5-29$ \\
\hline & LCD & $10-2$ & $9-22$ & $10-12$ & & LCD & $10-1$ & $9-27$ & $10-5$ \\
\hline \multirow{3}{*}{ Beijing } & FLD & $4-12$ & $4-3$ & $4-21$ & \multirow{3}{*}{ Luoyang } & FLD & $4-4$ & $3-29$ & $4-10$ \\
\hline & FFD & $4-18$ & $4-4$ & $5-2$ & & FFD & $4-27$ & $4-21$ & $5-3$ \\
\hline & LCD & $11-2$ & $10-23$ & $11-12$ & & LCD & $11-6$ & $11-2$ & $11-10$ \\
\hline \multirow{3}{*}{ Xi'an } & FLD & $4-1$ & $3-20$ & 4-13 & \multirow{3}{*}{ Shanghai } & FLD & $3-30$ & $3-13$ & $4-16$ \\
\hline & FFD & $4-12$ & $3-20$ & $5-5$ & & FFD & - & - & - \\
\hline & LCD & $11-4$ & $10-20$ & $11-19$ & & LCD & $11-30$ & $11-21$ & $12-9$ \\
\hline \multirow{3}{*}{ Wuhan } & FLD & $3-28$ & $3-18$ & $4-7$ & \multirow{3}{*}{$\begin{array}{l}\text { Hang- } \\
\text { zhou }\end{array}$} & FLD & $4-8$ & $3-29$ & $4-18$ \\
\hline & FFD & $4-13$ & $3-20$ & $5-7$ & & FFD & $4-14$ & $4-9$ & 4-19 \\
\hline & LCD & $11-14$ & $11-5$ & $11-23$ & & LCD & $11-2$ & $10-22$ & $11-13$ \\
\hline \multirow{3}{*}{ Chongqing } & FLD & - & - & - & \multirow{3}{*}{ Guiyang } & FLD & $3-17$ & $3-6$ & $3-28$ \\
\hline & FFD & - & - & - & & FFD & - & - & - \\
\hline & LCD & $11-20$ & $11-12$ & $11-28$ & & LCD & $11-14$ & $10-30$ & $11-29$ \\
\hline \multirow{3}{*}{ Guilin } & FLD & $3-16$ & $3-6$ & $3-26$ & \multirow{3}{*}{ Kunming } & FLD & $3-16$ & $3-9$ & $3-23$ \\
\hline & FFD & - & - & - & & FFD & $4-3$ & $3-10$ & $4-27$ \\
\hline & LCD & $11-1$ & $10-17$ & $11-16$ & & LCD & $10-26$ & $10-3$ & $11-18$ \\
\hline
\end{tabular}

Note: - indicates the fit is bad or cannot fit; numbers in the table represent month-date 
The peak of the tourism season varied between the different vegetation regions (Figure 3). Sites in subtropical evergreen broadleaf forest regions showed earlier peak (best) dates for viewing first leaves and full flowering and later peaks for viewing leaf coloring. In contrast, sites in temperate grassland regions and temperate coniferous and broadleaf mixed forest regions exhibited later best dates for viewing first leafing and full flowering and earlier best dates for viewing leaf coloring.

\subsection{Tourism season trends during the past 50 years}

The best date for viewing first leaves advanced (i.e., arrived earlier in the year) over the course of the past 50 years at 7 sites (Beijing, Xi'an, Shanghai, Harbin, Chongqing, Guiyang and Mudanjiang), and the trends were significant $(P<0.05)$ in Beijing, $\mathrm{Xi}$ ' an and Harbin. In contrast, the best dates for viewing first leafing in the other 5 sites were delayed, but only the delay at Luoyang was significant $(P<0.05$, Figure 4 and Table 4$)$.

The best date for viewing first flowering tended to advance in 8 sites (Beijing, Xi'an, Shanghai, Harbin, Kunming, Chongqing, Hangzhou and Guilin) over the past 50 years, with such advancement being significant $(P<0.05)$ in Beijing, Xi' an and Guilin. The best date for viewing first flowering became delayed in the other 4 sites, and the delays were significant $(P<0.05)$ at Wuhan and Mudanjiang (Table 4).

The best date for viewing leaf coloring only advanced in Hangzhou and Guilin and delayed in the other 10 sites, and the delays were significant $(P<0.05)$ in 5 sites (Beijing, Xi' an, Shanghai, Harbin and Chongqing) (Figure 5 and Table 4).

\subsection{Dependence of the tourism season on temperature}

Peak tourism season dates for first leafing, full flowering and leaf coloring correlated linearly with site temperature (Figure 6). The best date for viewing first leafing was determined 
(a) Harbin

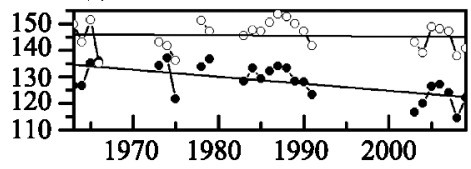

(c) Beijing

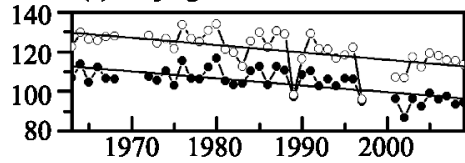

(e) Xi'an

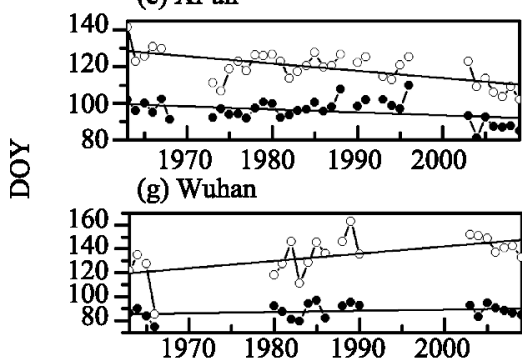

(i) Chongqing

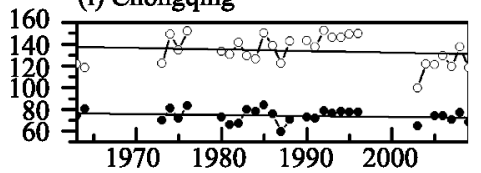

(k) Guilin

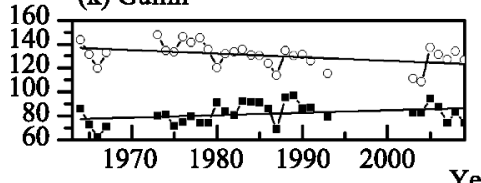

(b) Mudanjiang

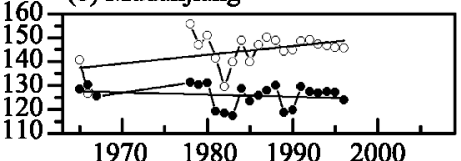

(d) Luoyang

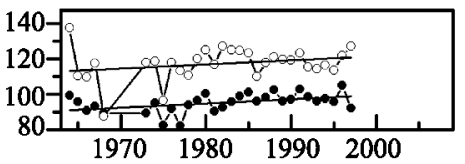

(f) Shanghai

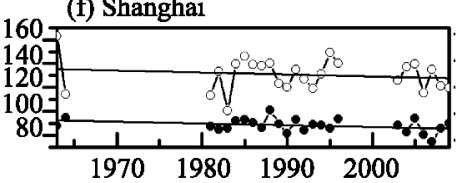

(h) Hangzhou

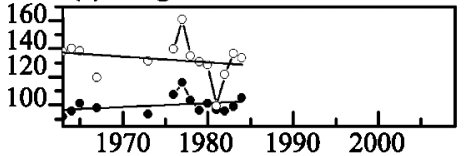

(j) Guiyang

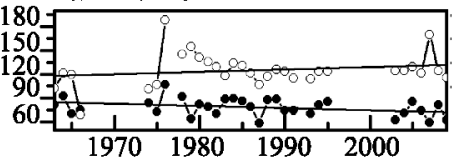

(1) Kunming

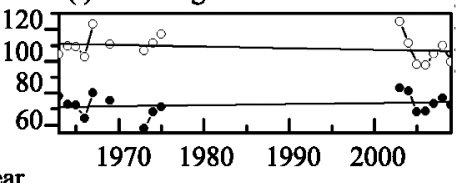

Figure 4 Peaks of the tourism season for first leafing and full flowering from 1963 to 2009 at each site Black dots represent first leafing dates, hollow dots represent full flowering dates; black straight lines indicate the linear fits to these data.

Table 4 Linear trends of the best dates for viewing the three phenophases at each site

\begin{tabular}{cccccccc}
\hline Sites & Phenophases & $\mathrm{R}$ & $\begin{array}{c}\text { Trend } \\
\text { (days/year) }\end{array}$ & Sites & Phenophases & $\mathrm{R}$ & $\begin{array}{c}\text { Trend } \\
\text { (days/year) }\end{array}$ \\
\hline \multirow{3}{*}{ Harbin } & FLD & $-0.63^{* *}$ & -0.26 & & FLD & -0.18 & -0.09 \\
& FFD & -0.06 & -0.02 & Mudanjiang & FFD & 0.45 & 0.37 \\
& LCD & $0.57^{* *}$ & 0.17 & & LCD & 0.29 & 0.16 \\
\hline \multirow{3}{*}{ Beijing } & FLD & $-0.69^{* *}$ & -0.35 & & FLD & 0.17 & 0.24 \\
& FFD & $-0.58^{* *}$ & -0.37 & Luoyang & FFD & 0.32 & 0.19 \\
& LCD & $0.36^{*}$ & 0.16 & & LCD & -0.67 & -0.28 \\
\hline \multirow{3}{*}{ Xi'an } & FLD & $-0.37^{* *}$ & -0.16 & \multirow{2}{*}{ Shanghai } & FLD & -0.33 & -0.15 \\
& FFD & $-0.63^{* *}$ & -0.4 & & FFD & -0.15 & -0.17 \\
& LCD & $0.51^{* *}$ & 0.21 & & FLD & 0.32 & 0.27 \\
Wuhan & FLD & 0.26 & 0.1 & & FFD & -0.22 & -0.41 \\
& FFD & $0.55^{* *}$ & 0.61 & Hangzhou & LCD & $-0.72^{*}$ & -0.71 \\
\hline \multirow{3}{*}{ Chongqing } & LCD & 0.26 & 0.18 & & FLD & -0.34 & -0.28 \\
& FLD & -0.2 & -0.09 & & FFD & 0.19 & 0.3 \\
& FFD & -0.14 & -0.14 & Guiyang & LCD & 0.27 & 0.15 \\
\hline \multirow{3}{*}{ Guilin } & LCD & $0.61^{* *}$ & 0.91 & & FLD & 0.2 & 0.07 \\
& FLD & 0.32 & 0.2 & & FFD & -0.25 & -0.1 \\
& FFD & $-0.41^{*}$ & -0.3 & Kunming & LCD & 0.32 & 0.21 \\
\hline
\end{tabular}

Note: $* * P<0.01, * P<0.05 ; R$ represents the goodness of linear fit. 
(a) Harbin

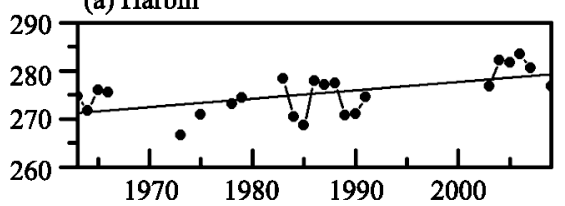

(c) Beijing

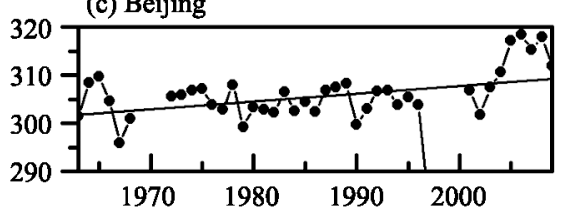

(e) Xi'an

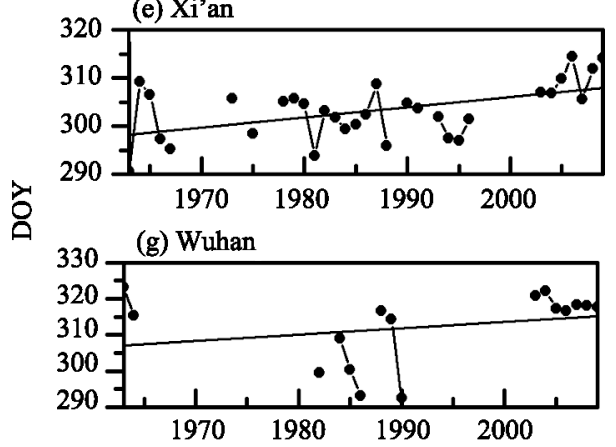

(i) Chongqing

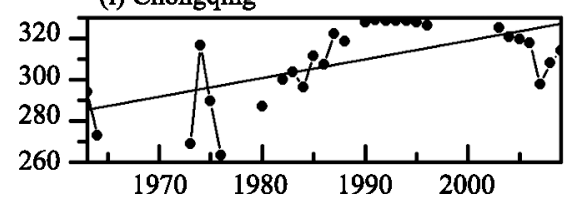

(k) Guilin

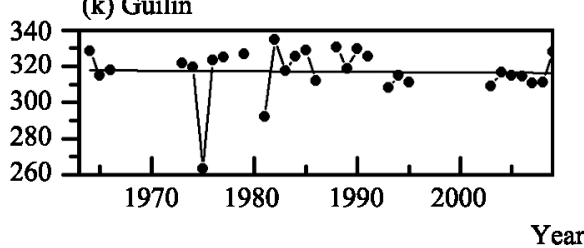

(b) Mudanjiang

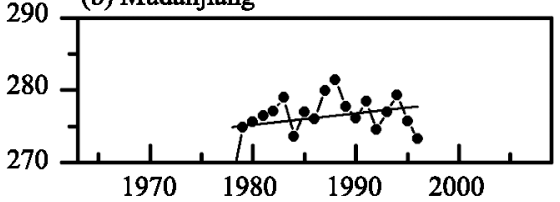

(d) Luoyang

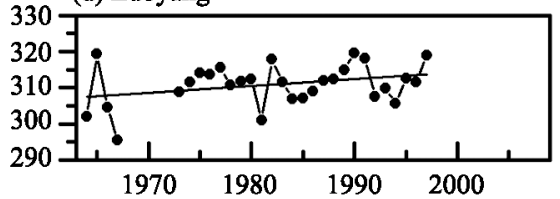

(f) Shanghai

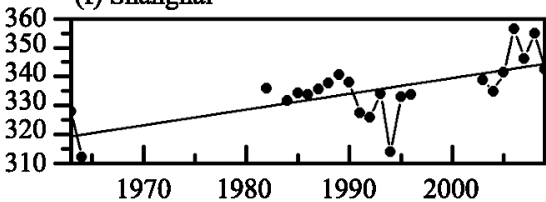

(h) Hangzhou
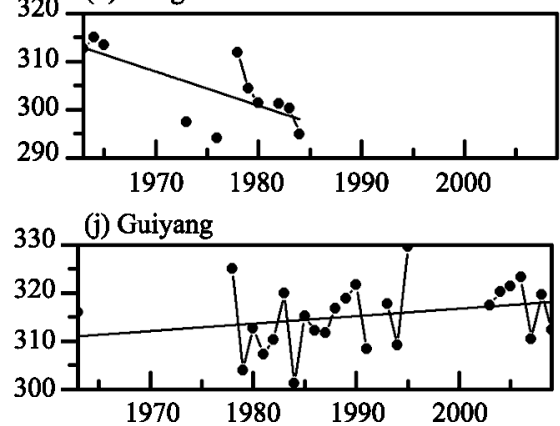

(l) Kunming

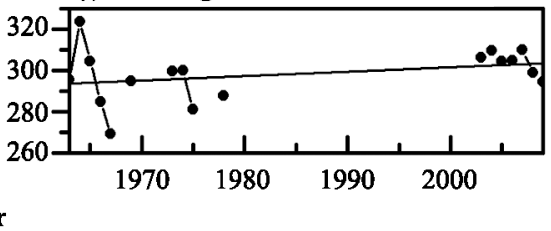

Figure 5 Peaks (black dots) of the leaf coloring tourism season from 1963 to 2009 at each site Black straight lines indicate the linear fits to these data.

to be negatively correlated with March-May temperature $(r=0.93, p<0.01)$, suggesting that the tourism season for first leafing was earlier in the sites with higher temperatures. The temperature sensitivity of the best date for first leafing viewing was -4.02 days $/{ }^{\circ} \mathrm{C}$ (where the negative sign indicates advancement in the date). The best date for viewing full flowering also showed a significant negative correlation with March-May temperature ( $r=0.94$, $p<0.01)$ and the temperature sensitivity was -4.04 days $/{ }^{\circ} \mathrm{C}$. The best date for viewing leaf coloring was positively correlated with site temperature $(r=0.85, p<0.01)$, indicating that the tourism season for leaf coloring was later in the sites with higher temperatures. The best date for viewing leaf coloring was delayed by 2.98 days per $1^{\circ} \mathrm{C}$ rise in site temperature. 


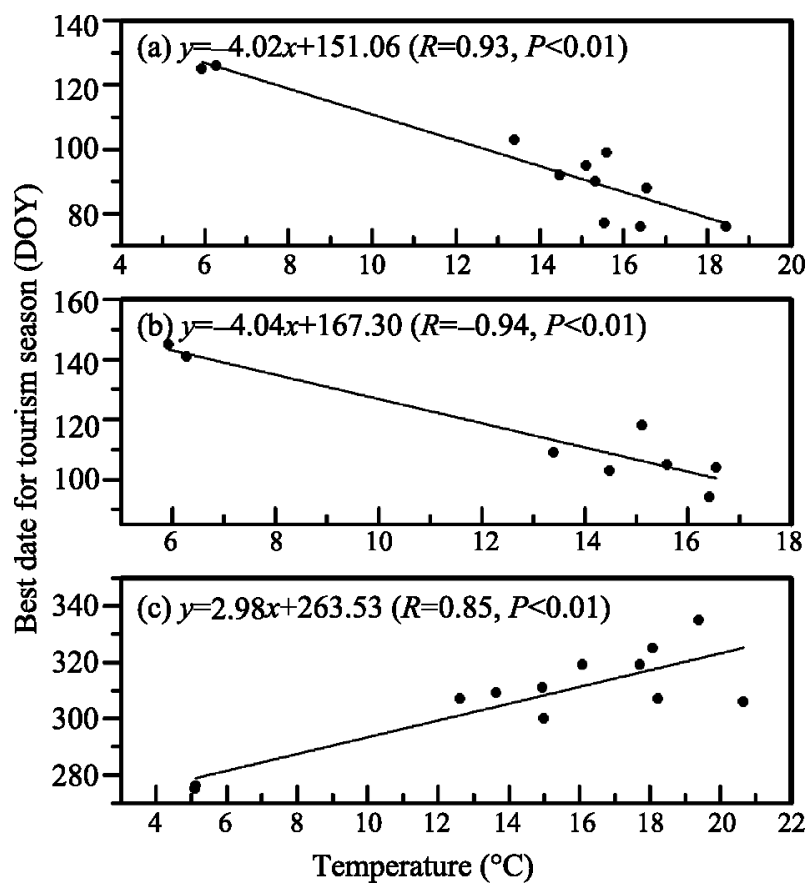

Figure 6 The relationship between the peak of the tourism season for (a) first leafing viewing and March-May temperature; (b) full flowering viewing and March-May temperature; (c) leaf coloring and September-November temperature at each site

\section{Discussion}

\subsection{The relationship between phenology and tourism}

In recent years, increasingly greater numbers of people have been participating in tourist activities involving viewing and admiring plants. The "Spring Flowering Economy", including the "Peach blossom festival", "Cherry blossom festival" and "rural tourism", has become a new economic growth engine. The tourism seasons for ornamental plants determined in this study provide tourist managers with a reference for when to hold viewing of plants and related festivals. In addition, the best dates for viewing first leafing and full flowering were shown in our work to be mainly between the end of March and the beginning of April, while the best dates for viewing leaf coloring were determined to range from early October to early November. These time periods are close to public holidays in China (Labor Day on May 1 and National Day on October 1) but do not perfectly overlap with them, suggesting that making flexible and rational holiday policies could help increase the income of these tourist destinations.

Besides determining the tourism season for ornamental plants, some studies have applied phenological models to forecast the phenophases of ornamental plants. For example, by measuring the weight of flower buds, researchers have produced exponential models to forecast the cherry blossom in Japan (Yashiaki, 1984). Zhang et al. (2005) used phenological models to forecast the first flower date of Prunus sargentii in Beijing Yuyuantan Park in 2002. Zhang et al. (2014) applied three phenological models to forecast the first flower dates 
and full flowering dates of three ornamental plants. Phenological models for accurately predicting phenophases of other ornamental plants are still needed, which would be useful for helping tourists arrange travel times.

\subsection{The reason for the difference changes of tourism season}

Temperature is the main factor influencing plant phenophases in temperate humid and semi-humid regions in the Northern Hemisphere (David and Paula, 2014). Changes in the tourism season in this study have mainly been triggered by changes in the temperature over the past 50 years. During this time period, climate warming has been relatively evident in north China, especially in the north of the Qinling Mountain-Huaihe River region and in parts of the Tibetan Plateau. However, temperatures have not increased significantly in south China (including the Sichuan Basin and Yunnan-Guizhou Plateau), and has even declined in some regions (ECCNAR, 2007). Such differences in the change in temperature over the past 50 years between different locations have resulted in the 12 sites of our study displaying different changes of the tourism season during this time period. In addition, previous studies have demonstrated that phenological sensitivity in response to change in temperature varies greatly between different plants (Dai et al., 2014; Richard et al., 2009), which is another reason why the 12 sites have displayed different tourism season trends.

\subsection{Spatial pattern of the tourism season}

Previous studies have proved that the timing of plant phenophases follow a latitudinal gradient (Hopkins, 1920; Han et al., 2008). The results of the current study also suggest that the peak of the tourism season has correlated significantly with latitude (Figure 7). The best date for viewing first leafing was shown to correlate positively with latitude $(R=0.96, P<0.01)$, with a delay of 2.26 days per $1^{\circ}$ increase in latitude. The best date for viewing full flowering was also shown to correlate positively with latitude $(R=0.91, P<0.01)$, here with a sensitivity of 2.25 days $/{ }^{\circ}$. The best date for viewing leaf coloring was shown to correlate negatively with latitude $(R=-0.67$, $P<0.05$ ), advancing by an average of 1.46 days per $1^{\circ}$ increase in latitude. Tourists could thus arrange their tour routes according to such spatial patterns. For example, since the tourism seasons for first leafing and full flowering are earlier in the south, tourists could travel from south to north to optimize the amount of time that can be dedicated to viewing these pheno-

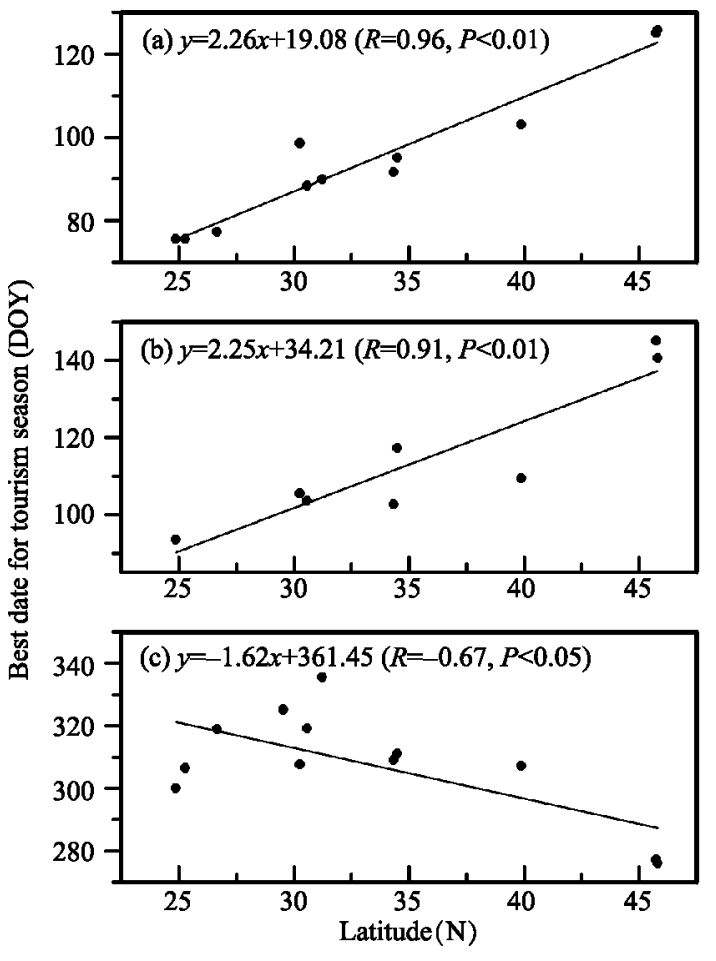

Figure 7 Peaks of the tourism season for viewing (a) first leafing, (b) full flowering, and (c) leaf coloring at different latitudes 
phases.

The species of plants investigated in the 12 sites differ, which may lead to some uncertainties in determining the tourism season. To verify the accuracy of our results, we analyzed the spatial patterns of the full flowering dates of two typical ornamental plants, Amygdalus davidiana and Cerasus yedoensis (Figure 8). The results showed that these dates were in both cases significantly correlated with latitude, with delays of 1.96 days and 2.03 days per $1^{\circ}$ increase in latitude, respectively. These results are very close to the latitudinal dependence of the peak of the tourism season for full flowering dates of different plants $\left(2.25\right.$ days $\left.^{\circ}{ }^{\circ}\right)$. Therefore, frequency distribution analysis is a feasible method to determine tourism season.

\subsection{Future tourism season trends}

The 4th and 5th assessment reports of the Intergovernmental Panel on Climate Change (IPCC) stated that temperatures may continue to increase by $1.5^{\circ} \mathrm{C}-2^{\circ} \mathrm{C}$ in the future (IPCC, 2013; IPCC, 2007), suggesting a continuation of the changes in plant phenophases. Ge et al. (2013) predicted how first leafing dates would change for 20 plants in the 21 st century in China based on a CCSM 3 climate simulation. The results suggested that first leafing dates would advance in the future. In addition, many studies have indicated that this trend would be more noticeable in early-season plants (Ge et al., 2013; Bai et al., 2011; Miller et al., 2008). These predictions suggest that the peak of the tourism season for leaf and flowering viewing will come earlier, and that the tourism season will become longer. Since the response of leaf coloring date to climate warming is opposite that of the first leafing and full flowering dates, the tourism season for leaf coloring viewing would be delayed in the future.

\subsection{Uncertainties}

First, the differences in plant species and their numbers between the 12 sites may have introduced some error into the determination of the tourism season. Secondly, there were model errors of 1-5 days when applying the normal distribution function to fit the frequency distributions of the phenophases. In addition, in several sites such as Harbin, Kunming, Guilin and Wuhan, phenological data were missing for a few of the years during the study period, which may have affected the estimates of the phenological trends.

\section{Conclusions}

In this study, we used frequency distributions to determine the tourism seasons for first leafing, full flowering and leaf coloring of ornamental plants in 12 sites across the eastern half 
of central and eastern China. Changes in the peaks of the tourism season over the past 50 years and the dependence of the tourism season on location were also analyzed. The main conclusions are as follows:

(1) The peak of the tourism season varied in different vegetation regions. For example, the tourism seasons for viewing first leafing and full flowering were earlier, and that for viewing leaf coloring was later in subtropical evergreen forests than in temperate coniferous-deciduous broadleaf mixed forests. Accordingly, tourists could pay attention to these differences when arranging their schedules to view and admire distinctive plants.

(2) The peaks of the tourism season changed over the past 50 years to different degrees at different sites. The best dates for viewing first leafing and full flowering advanced significantly, and that for viewing leaf coloring became significantly delayed in Beijing, Xi' an and Harbin. The interannual change in the tourism season directly indicates the influence of climate change on tourist activities.

(3) The peak of the tourism season correlated significantly with temperature. The best date for first leafing and full flowering advanced, respectively, by 4.02 days and 4.04 days per $1{ }^{\circ} \mathrm{C}$ increase in spring (March-May) temperature. The best date for leaf coloring correlated significantly and positively with September-November temperature and the spatial sensitivity was 2.98 days $/{ }^{\circ} \mathrm{C}$. The result clearly showed that temperature was the main factor determining the emergence of the plant landscape. Due to the north-south temperature gradient, the best dates for viewing first leafing and full flowering were earlier and the best date for viewing leaf coloring was later at lower latitudes. Accordingly, tourists could travel from south to north in the spring and from north to south in the autumn to optimize viewing and admiring activities of the most desirable phenophases along the way.

\section{References}

Bai Jie, Ge Quansheng, Dai Junhu et al., 2010. Relationship between woody plants phenology and climate factors in Xi'an, China. Chinese Journal of Plant Ecology, 34(11): 1274-1282. (in Chinese)

Bai Jie, Ge Quansheng, Dai Junhu, 2011. The response of first flowering dates to abrupt climate change in Beijing. Advances in Atmospheric Sciences, 28(3): 564-572.

Bao Jigang, Chu Yifang, 2012. Tourism Geography. Beijing: Higher Education Press. (in Chinese)

Bell S, Tyrväinen L, Sievänen T et al., 2007. Outdoor recreation and nature tourism: A European perspective. Living Reviews in Landscape Research, 1(2): 1-46.

Chen Lingling, 2007. Study on the exploitation of the cheery tourism in Japan. International Workshop on Chinese Flower Culture, 11-14. (in Chinese)

Chen Xiaoqiu, Cao Zhiping, 1999. Frequency distribution patterns of plant phenophases and its application to season determination. Scientia Geographica Sinica, 19(1): 21-27. (in Chinese)

Cleland E E, Chuine I, Menzel A et al., 2007. Shifting plant phenology in response to global change. Trends in Ecology and Evolution, 22(7): 357-365.

Dai Junhu, Wang Huanjiong, Ge Quansheng, 2013. Multiple phenological responses to climate change among 42 plant species in Xi'an, China. International Journal of Biometeorology, 57(5): 749-758.

Dai Junhu, Wang Huanjiong, Ge Quansheng, 2014. The spatial pattern of leaf phenology and its response to climate change in China. International Journal of Biometeorology, 58: 521-528.

David A Springate, Paula X Kover, 2014. Plant responses to elevated temperatures: A field study on phenological sensitivity and fitness responses to simulated climate warming. Global Change Biology, 20(2): 456-465.

Editorial Committee of China's National Assessment Report on Climate Change (ECCNAR), 2007. China's Na- 
tional Assessment Report on Climate Change. Beijing. Science Press, 1-422. (in Chinese)

Ge Quansheng, Dai Junhu, Liu Jun et al., 2013. The effect of climate change on the fall foliage vacation in China. Tourism Management, 38: 80-84.

Ge Quansheng, Wang Huanjiong, Dai Junhu, 2013. Simulating changes in the leaf unfolding time of 20 plant species in China over the twenty-first century. International Journal of Biometeorology: 1-12.

Ge Quansheng, Wang Huanjiong, Zheng Jingyun et al., 2014. A 170 year spring phenology index of plants in eastern China. Journal of Geophysical Research, 119(3): 301-311.

Han Chao, Ding Deping, Li Xun, 2008. Study on the spatial and temporal distribution of phenological seasons in China. Beijing: Chinese Meteorological Society, 15-21. (in Chinese)

Hopkins A D, 1920. The bioclimatic law. Monthly Weather Review, 48: 355-355.

Hou Xueyu, 2001. 1:1000000 Vegetation Atlas of China. Beijing: Science Press, 241-243.

IPCC, 2013. Summary for Policymakers. Climate Change 2013: The Physical Science Basis. Contribution of Working Group I to the Fifth Assessment Report of the Intergovernmental Panel on Climate Change, Stocker T F, Qin D, Plattner G K et al., Cambridge, UK: Cambridge University Press, 3-29.

IPCC, 2007. Summary for Policymakers. Climate Change 2007: Impacts, Adaptation and Vulnerability. Contribution of Working Group II to the Fourth Assessment Report of the Intergovernmental Panel on Climate Change, Solomon S, Qin D, Manning M et al., Cambridge, UK: Cambridge University Press, 7-22.

Ma Li, Fang Xiuqi, 2006. Effects of global warming on seasonal tourism for the last 20 years in Beijing: A case study on the Peach Flower Stanza of Beijing Botanical Garden. Advances in Earth Science, 21(3): 313-319. (in Chinese)

Menzel A, Sparks T H, Estrella N et al., 2006. European phenological response to climate change matches the warming pattern. Global Change Biology, 12(10): 1969-1976.

Miller-Rushing A J, Inouye D W, Primack R B, 2008. How well do first flowering dates measure plant responses to climate change? The effects of population size and sampling frequency. Journal of Ecology, 96(6): 1289-1296.

Richard B Primack, Inés Ibáñez, Hiroyoshi Higuchi et al., 2009. Spatial and interspecific variability in phenological responses to warming temperatures. Biological Conservation, 142(11): 2569-2577.

Yang Yunfei, Zhu Tingcheng, 2011. Plant Ecology. Beijing: Higher Education Press, 267-269. (in Chinese)

Yashiaki Mihara, 1984. Practical Agricultural Meteorology. Nanning: Guangxi People's Publishing House, 1-165. (in Chinese)

Zhang Aiying, Wang Huanjiong, Dai Junhu et al., 2014. Applicability analysis of phenological models in the flowering time prediction of ornamental plants in Beijing area. Journal of Applied Meteorological Science, 25(4): 483-492. (in Chinese)

Zhang Mingqing, Yang Guodong, 2006. Curriculum design of tourism phenology. Journal of Capital Normal University, 27(1): 73-74, 58. (in Chinese)

Zhang Mingqing, Yang Guodong, Xu Xiaobo, 2005. The use of flower bud measurements for forecasting florescence in Prunus Sargentii. Acta Phytoecologica Sinica, 29(4): 610-614. (in Chinese) 